\title{
Use of a Remote Network Lab as an Aid to Support Teaching Computer
}

\author{
Marco A. Aravena \\ Universidad de Valparaíso, Departamento de Computación, \\ Valparaiso, Chile \\ marco.aravena@uv.cl \\ and \\ Andrés A. Ramos \\ Universidad de Valparaíso, Facultad de Ciencias, \\ Valparaíso, Chile \\ andres.ramos@uv.cl
}

\begin{abstract}
This article presents the use of a remote network lab as an aid to support teaching computer networks. The purpose is to enable students complement their theoretical learning with practical experimentation in networking devices which can be carried out synchronously to theoretical classes and from any room with internet access. Unlike the current solutions based on mainly software emulation and simulation, the students interact remotely with commercial network devices, such as cutting-edge and widely used switches, routers and firewalls at the workplace.This proposal reduces the expenses or installing new laboratories in all the campuses where lectures are held and also moving the students to laboratories that are not located near their classrooms. The use of the remote laboratory has been compared with the use of traditional network labs with senior students majoring information technology engineering. The preliminary results show a great similarity in both uses demonstrating that a remote network lab is an effective aid for teaching computer networks..
\end{abstract}

Keywords: Aid tool, Remote lab, Teaching networks, Information and Comunnication Technologies.

\section{INTRODUCTION}

The Computing Engineering Curriculum consists of a group of areas that develop basic skills to be used when the graduated engineer works. These topics are divided into 5 specialized disciplines: Computing Engineering, Computer Science, Information Systems, Information Technologies and Software Engineering. The study program of an engineer should comprise all these disciplines.

The ACM IEEE in [1] shows each of the topics that should be taught in each discipline along the years of study. In this document, the importance of the network and connectivity teaching can be appreciated for each of them in the study plan of a computer science engineer. Then the arising questions are: ¿what are the most relevant topics that should be taught? ¿Is it necessary to do lab practices or is it enough with the theoretical approaches?

The answers to these questions are found in the document called "Guidelines to computer support in a network environment" ACM [2], where some content areas and the topics associated to them are identified, such as, organization environment, documentation and technical reference, hardware and software, among others. In this document, it is remarked the need to have the necessary elements to allow the student to interact with different devices of connectivity. The above is reinforced by Workshop on Computer Networking: Curriculum Designs and Educational Challenges[3], where the participants agree on the need to have laboratories implemented with connectivity elements, to teach networks. 
Moreover, IEEE ACM in [1-2], as well as in the different organizations participating in the Workshop on Computer Networking [4] agree with the idea that teaching computer networks should be divided into $60 \%$ theory and $40 \%$ practice.

Therefore, it can be concluded that it is important to teach theory and practice to engineer students, being more relevant in Information and Communications Technologies (ICT), the engineer has to deal directly with both network software and hardware..

\section{USE OF LABOratories as a TeaChING AID.}

A network lab consists of a room that has network equipment such a switch, router, firewall and computers. With this equipment the students can put into practice the knowledge learned from theory about computer network.

However, the purchase of these devises and lab maintenance is expensive. The implementation and maintenance of a laboratory like this is around US\$50.000

In Table 1 is listed, as example, the equipment of the Network Laboratory of the Computer Department, of Universidad de Valparaiso, Chile.

Table 1: Network Lab Equipment of Computer Science at Universidad de Valparaíso

\begin{tabular}{ccc}
\hline Item & Quantity & Description \\
\hline 1 & 13 & Computers: \\
& & Processor Pentium IV 3GHZ. \\
& 3 Networks cards & RAM 256 MB \\
& & Hard Drive $: 30-40 \mathrm{~GB}$ \\
& CD Reader \\
& & $15^{\prime \prime}$ Monitors, flat screen (LCD) \\
\hline 2 & 4 & Router Cisco 2600 :12.x, 2 Seriales ports, 2 Ethernet ports \\
\hline 3 & 4 & Switch Cisco Catalyst 2950-24 : 24 x 10/100 ports \\
\hline 4 & 4 & Switch 3com 4500 26 x 10/100, 2 x 10/100/1000 ports \\
\hline 5 & 4 & Firewall Cisco PIX 506E, 2 Ethernet ports, 1 console port, 32MB RAM \\
& & memory, 8MB FLASH memory. \\
\hline 6 & 2 & Racks, 19" wide : glass doors \\
\hline 7 & 4 & Patch Panel 48 ports \\
\hline
\end{tabular}

Due to the high costs, it is not possible to implement a network laboratory in all physical locations where where they are teaching computer networks..

The traditional approach to teach network computers, that includes theory and practice, consists of implementing a network lab, lecturing network in a classroom and later taking the students to a network lab.
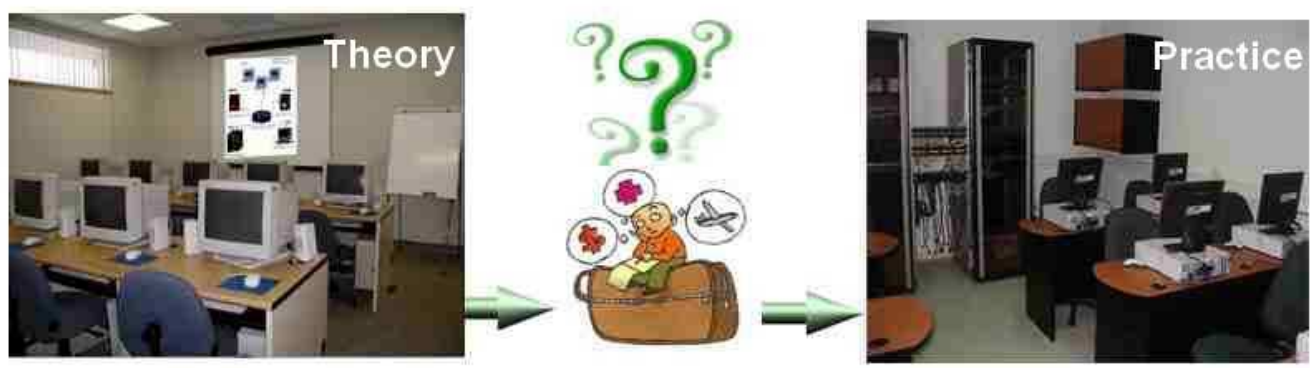

Figure 1: Tradicional Teaching in Networks Computers 
This approach has the following problems:

a) A teacher or assistant, to monitor the activities achieved by the students, is always required at the lab. This reduces the availability of the lab to the students.

b) Lab activities can only be done face to face. There is no option of distance working.

In case teaching is done away from the lab:

d) Students can not be transferred from the classroom to the place where the lab is located because of student's availability or because of geographic distances.

e) Labs can not be carried to the teaching place.

f) It s not possible to implement a lab in each room where teaching is held because it is very expensive.

\section{EXISTING Methods AND TOOLS TO REMote SUPPORT FOR TEACHING.}

There are several solutions to meet the requirements of equipment to support network teaching. Some of them are shown in Table 2.

Table 2: Solutions to support computer networks teaching.

\begin{tabular}{|c|c|c|c|c|}
\hline Project & Creator & $\begin{array}{c}\text { Remote } \\
\text { Access }\end{array}$ & Approach & $\begin{array}{c}\text { Allow } \\
\text { Configuration }\end{array}$ \\
\hline $\begin{array}{l}\text { "The Open Network Laboratory" } \\
{[6]}\end{array}$ & $\begin{array}{l}\text { Universidad de } \\
\text { Washington }\end{array}$ & Yes & Real Devices & $\mathrm{NO}$ \\
\hline $\begin{array}{l}\text { "Didactical Issues of a Remote } \\
\text { Network Laboratory" [7] }\end{array}$ & $\begin{array}{l}\text { Universidad de } \\
\text { Bern Alemania }\end{array}$ & Yes & Real Devices & SI \\
\hline "Remote Real Laboratory" [8] & Universidad de Génova & Yes & Real Devices & SI \\
\hline $\begin{array}{l}\text { Remote Lab for teaching TCP /IP } \\
\text { Networks [9] }\end{array}$ & $\begin{array}{l}\text { Universidad de Girona, } \\
\text { España }\end{array}$ & Yes & Real Devices & NO \\
\hline $\begin{array}{l}\text { Model for interactive technologies } \\
\text { based remote lab education [10] }\end{array}$ & $\begin{array}{c}\text { Universidad de } \\
\text { Massachussets Amherst }\end{array}$ & Yes & Real Devices & SI \\
\hline $\begin{array}{c}\text { Real Access } \\
\text { Laboratory [11] }\end{array}$ & HP invent & Yes & Real Devices & SI \\
\hline CCNA Network Visualizer 5.0 [12] & CISCO & NO & EMULATOR & SI \\
\hline Network Simulator [14] & $\begin{array}{l}\text { Universidad Autónoma } \\
\text { de Bucaramanga }\end{array}$ & $\mathrm{NO}$ & SIMULATOR & SI \\
\hline IMUNES [5] & University of Zagreb & $\mathrm{NO}$ & SIMULADOR & SI \\
\hline
\end{tabular}

However, none of these tools is a teaching aid system based on interaction and configuration of commercial network equipment as the equipment of Universidad de Valparaíso described here.

\section{Proposal: The USE of Remote NeTworks LABoratory}

This article presents a new proposal consisting on using a remote network laboratory to aid teaching computer networks. The main objective is that the student be able to complement his/her theoretical learning through practical experiences with network devices located in a network laboratory (see Fig. 2). 


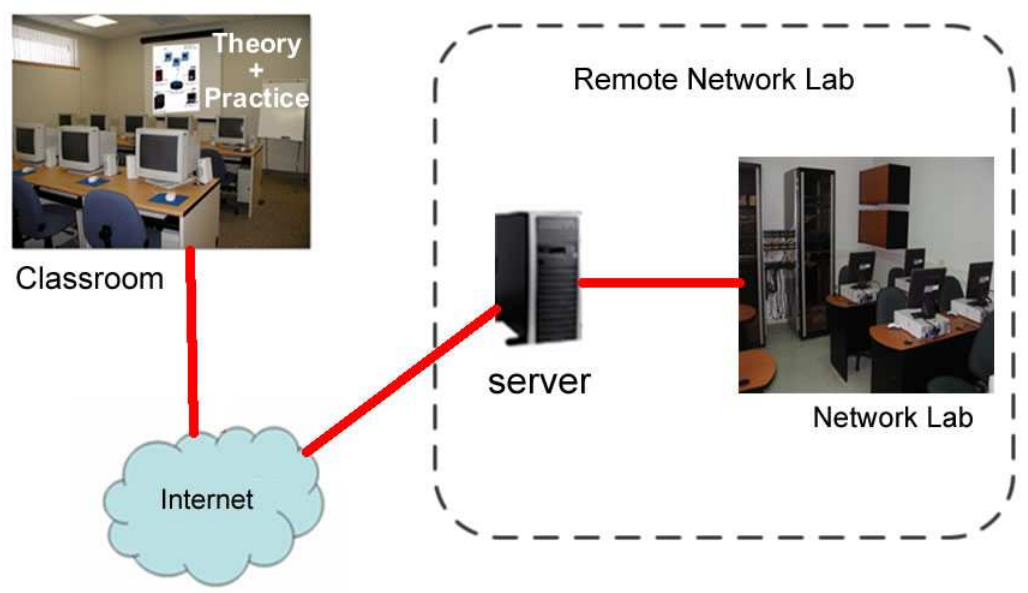

Figure 2: Remote networks laboratory as an aid to teaching computer networks.

The proposal of using a remote laboratory presents the following advantages:

- It reduces the costs of implementation. It only requires to install a network lab to be shared by different lecturers simultaneously.

- It increases the schedule availability of the laboratory. The students can access to the lab simultaneously with the network lecture, anytime and from anywhere.

- It increases the geographic availability. A network course with theoretical and practical classes, can be taught from anywhere with internet connection.

- There is independence to choose any make and model devices. Any brand name or type of device can be useful for interacting.

\section{IMPLEMENTING THE PROPOSAL}

The setting up is a system that allows the access to a remote lab from Internet. A student plays the role of a client who accesses via Internet to a connectivity server. This server lets the students interact with the equipment located in the network lab (router, firewall, switch, computers, etc) since this is connected with the laboratory devices. This system consists of the elements indicated in Table 3 and their interconnection is shown in Fig 3.

Table 3: Components of the remote network lab.

\begin{tabular}{cc}
\hline Element & Implementation \\
\hline $\begin{array}{c}\text { Remote Client (student } \\
\text { in a classroom) }\end{array}$ & Web Browser, Internet Explorer / Mozilla. \\
Internet Connection \\
\hline Server & FreeBSD Operating System. \\
& JBoss Aplications Server. \\
& Postgres SQL DBMS. \\
Java JDK 1.5. \\
Serial Multiport Card. \\
Parallel Port Connection. \\
J2EE Aplication Developed. \\
\hline Labs Computers & FreeBSD Live CD with serial console. \\
& Available serial port .
\end{tabular}




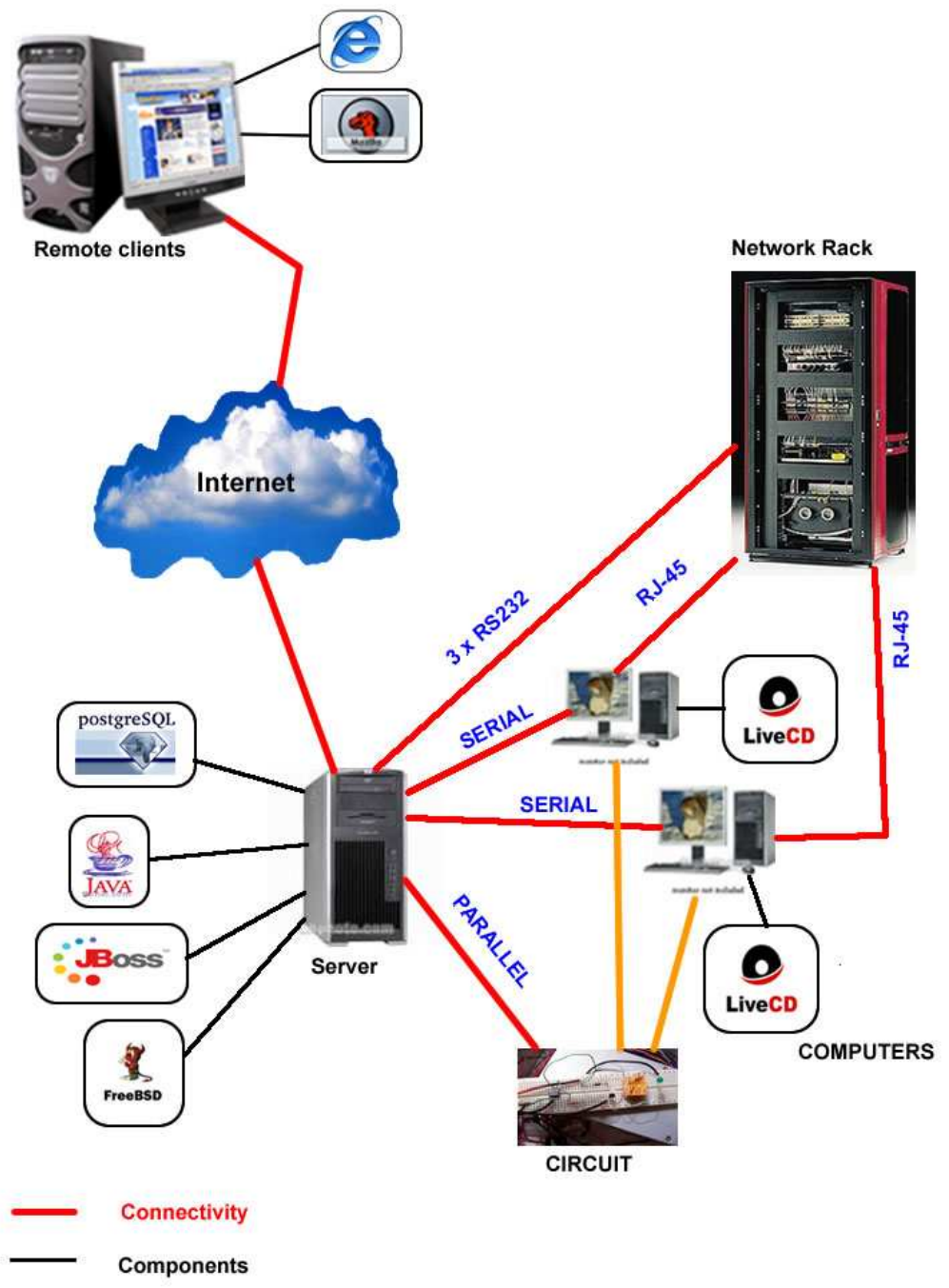

Figure 3: Interconnection of components of the remote network lab.

\section{TEST AND VALIDATION}

The evaluation of the use of the remote network laboratorios as supporting teaching in computer network consist of comparing this proposal with the traditional approach. To achieve this, the following questions should be answered:

- How long does a student take to complete the checklist of an activity using a remote lab versus a face to face

lab?

- What is the efficiency reached? (Time and completeness)

- What is the user's satisfaction?

- Are there meaningful differences in relation with the face to face practice in the lab?

Due to the exploring character of this validation, the experiment guidelines are determined through the objectives, for example, characterizing the impact of the remote tool of the network configuration on the student's learning. In particular, to contrast the efficiency obtained by the student by means of the remote tool used, as compared to the face to face method in the resolution of a cycle of lab activities.

The test pursues the study of the effect of using a specific tool to teach how to configure network equipment. This shows, as an independent variable, the tool used. And as a dependent variable, the efficiency achieved by configuring the network equipment.

Based on the scope and objective set, it was established that this research is a quasi experiment, with many tests and a control group, in which case, the variable is given by the presence or absence of the remote tool. 


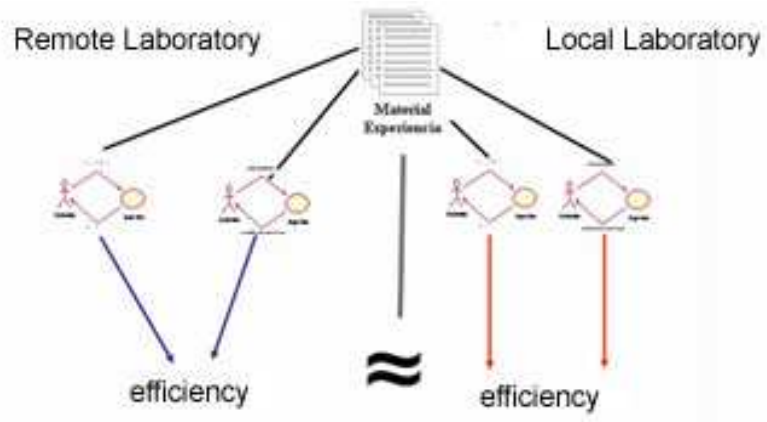

Figure 4: Shows the general outline of the experiment (the expected efficiency result).

Fig. 4 shows the general outline of the experiment. Both groups of students (face to face and remote) perform the same activities. The control group is the team working face to face. Thus, it is expected similar results in the efficiency in both groups.

To achieve the experiences the following sequence is carried out as it shown in Fig. 5.

1.- Both groups receive the same class notes.

2.- An initial test is given to both groups.

3.-The group is divided into a control group (local laboratory) and experimenting group ( remote laboratory) to perform the experience.

4.- To finish each cycle, both groups have a final test, evaluating the learning acquired.

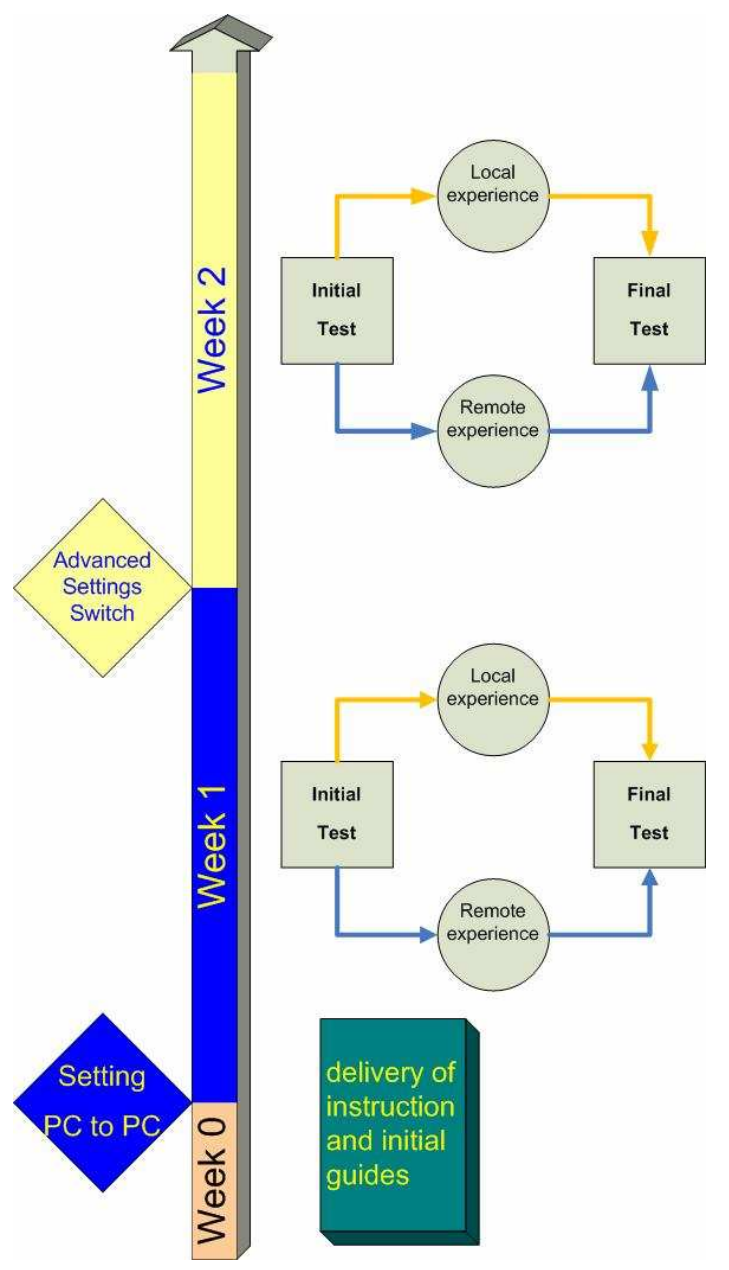

Figure 5: Experiment sequence. 
The activity shown in fig 5 is achieved in 3 sessions (every session in a different week), in which both methodologies are carried out. The detail is as follows:

- Session 0: Handing out checklists and directions for the activity. The students are also informed about the timetable, deadlines and processes.

- Session 1: Activity of "Configuration from PC to PC, and basic commands of connectivity". Before beginning, personal data of participants' profile is obtained through a survey. Later, an initial test, a checklist and a final test are given to both face to face and remote students.

- Session 2: Activity of "Advanced configuration of Switch (VLAN)". Students are given tests, as in session 1. Once the activity is over, the students have to answer the satisfaction survey.

\section{RESULTS}

The results obtained in the different evaluations are shown in Table 4, 5 and 6 . In Table 4 the results of initial test are showed with range, 0 (very bad) to 100 (excellent). In both experiences, the initial test had a very similar results by using the local and remote lab.

Table 4: Results of the Initial Test

\begin{tabular}{lcc}
\cline { 2 - 3 } & Local & Remote \\
\hline Experience 1 & 57.1 & 62.5 \\
\hline Experience 2 & 90 & 92.5 \\
\hline
\end{tabular}

Table 5: Check list execution time (hh:mm:ss)

\begin{tabular}{lcc}
\cline { 2 - 3 } & Local & Remote \\
\hline Experience 1 & $0: 37: 00$ & $0: 20: 20$ \\
\hline Experience 2 & $0: 41: 40$ & $0: 28: 00$ \\
\hline
\end{tabular}

Table 6: Results of the Final Test

\begin{tabular}{lcc}
\cline { 2 - 3 } & Local & Remote \\
\hline Experience 1 & 73.5 & 89.3 \\
\hline Experience 2 & 80 & 85 \\
\hline
\end{tabular}

In the case of the checklist (Table 5), time is taken into account only if the students complete it $100 \%$, since all the students can answer it completely

It can be clearly seen that learning results are better in the remote lab not only on the time taken to do the activity but also regarding tests results.

Therefore, the average efficiency obtained in the remote activity is better than the results obtained in the face to face activity. The opposite happens with the face to face activity in which efficiency diminishes. The increase of the efficiency can be influenced by the fact that there are no distractive elements, such as the students gathering at the patch panel to connect the equipment. In the remote case, the students are focused to use only the commands, avoiding all the distracting factors that can take place in a face to face lab.

To get more conclusive data, it is necessary to apply the experiment:

- With more students

- Doing more exercises than activities are usually performed.

- $\quad$ Repeating the activity several times and in different universities.

With the above conditions and taking a control group that represents a normal course of network lab and one similar using a remote tool, more representative results can be obtained for this activity. However the trend showed by the results points out that the remote tool described in this paper is an effective tool for leaning computer network through the configuration of network equipment and a support equivalent to a face to face laboratory 


\section{CONCLUSIONS}

In this article, It is described a new methodology for a remote network lab as a tool to support teaching of computer network. This proposal allows the student to complement the learning of the theory and practical (hands-on) experimenting in network devices simultaneously (synchronously?)with theoretical classes and from any room with Internet access. Unlike the current solutions, this proposal allows the interaction with cutting edge commercial devices widely used at the workplace.

The validation of the use of the remote network lab is compared with the traditional method of teaching. To do this , some tests are given to senior students of Computer Engineering. Results show a great similarity between both face to face and remote, but the trend is to get better results with this proposal. This shows that the use of a remote lab is actually a support to the teaching of computer network.

\section{REFERENCES}

[1] Russell Shackelford, James H. Cross II, Gordon Davies, John Impagliazzo, Reza Kamali, Richard LeBlanc, Barry Lunt, Andrew McGettrick, Robert Sloan, and Heikki Topi. Computing curricula 2005. ACM IEEE Computer society, the Computing Curricula Series(1):(5\{50):62, Septiembre 2005.

[2] Karl Klee Chair, Richard Austing, Robert Campbell, C.Fay Cover, and Joyce Currie Little. Guidelines for associate degree programs to support computing in a networked environment. ACM Association for Computing Machinery,(1):(5\{30):39, Marzo 2000.

[3] JohnP.Abraham, EhabAl-Shaer, and Greg Brewster. Workshop on computer networking: Curriculum designs and educational challenges. ACM SIGCOMM, pages (2\{10):59, Agosto 2002. Paper Pubicados en el Workshop.

[4] Ann Burroughs. Laboratory courses. Humboldt State University, Agosto 2002. presentación en Workshop on Computer Networking: Curriculum Designs and Educational Challenges.

[5] University of Zagreb. imunes, simulador de redes, 2006. Página principal del simulador, en la cual, se encuentra la descripción y manual de usuario. Dirección: http://www.tel.fer.hr/imunes/

[6] John Dehart, Fred Kuhns, Jyoti Parwatikar, Jonathan Turner, and Ken Wong. The open network laboratory. Washington University, St. Louis, Article 1:3, 2003.

[7] Marc-Alain Steinemann, Stefan Zimmerli, Thomas Jampen, and Torsten Braun. "architectural issues of a remote network laboratory". Institut fäur Informatik and Angewandte Mathematik, Universität Bern Neubrückstr.

[8] Alasane Diop and Amine Berqia. Remote real laboratory. Universidad de Genova, pages 1\{4:4, 2003.

[9] Lluis Fábrega, Jordi Massaguer, and Teodor Jove y Ramón Fabregat. Laboratorio remoto para la enseñanza de redes TCP/IP. Instituto de Informática yAplicaciones. Universidad de Girona.

[10] Aura Ganz Ji Hua. A new model for remote laboratory education based on next generation interactive technologies. Universidad de Massachussets Amherst, 2005. Proyecto de tesis doctoral.

[11] HP Invent. Laboratorios de acceso remoto. http://h30095.www3.hp.com. Venta y Descripción del Sistema.

[12] Cisco Systems. Producto routers sims. Dirección: http://www.routersim.com. Venta y Descripción del Simulador.

[13] Marc-Alain Steinemann and Torsten Braun. Remote versus traditional learning in a computer networks laboratory. Institut fäur Informatik und Angewandte Mathematik, UniversitÄat Bern NeubrÄuckstr., page 10, 2002. Informe realizado, sobre educación presencial v/s educación remota.

[14] Universidad Autónoma de Bucaramanga. Network simulator (ns), 2006. Página principal del simulador, en la cual se describe el sistema, además de encontrar el manual de usuario y la aplicación, bajo licencia GLP. 